\title{
RESEÑA \\ DISYUNTIVA DE AMÉRICA LATINA: POLÍTICA DE ESTADO O DE MERCADO
}

Guadalupe Margarita González Hernández*

on una visión distinta a la de los estudios del desarrollo, sea en su vertiente principal o su versión crítica, el trabajo de Peter Kingstone The Political Economy of Latin America ${ }^{1}$ se sumerge en una discusión harto compleja, pero a la vez trasmitida suavemente, sobre la historia socioeconómica de América Latina en los últimos cien años.

Desde el principio, Kingstone interpuso su posición teórica: no enaltece al modelo de desarrollo neoliberal ni defiende al modelo de Industrialización por Sustitución de Importaciones (ISI), impuestos en distintas etapas históricas del siglo veinte en el subcontinente latinoamericano. Tampoco adquiere un matiz crítico de todos los modelos de desarrollo implantados. Al contrario, su visión es identificar cuáles han sido los aciertos y desaciertos de dichos modelos que han provocado, por un lado, el surgimiento de la izquierda como propuesta política-electoral y, por otro lado, reconocer e identificar por qué dichos modelos han sido altamente criticados y reformados hacia el fortalecimiento de las instituciones y la gobernanza bajo una visión distinta a la de los institucionalistas.

\footnotetext{
* Docente investigadora de la Unidad Académica de Estudios del Desarrollo de la Universidad Autónoma de Zacatecas, México.

${ }^{1}$ Peter Kingstone (2011), The Political Economy of Latin America, Routledge, New York, pp. 177.
} 
Bajo la estructura de cinco apartados, Kingstone ofrece un argumento de forma expedita y coherente de que es necesario, al analizar a América Latina, hacerlo con precaución: la realidad de la región es heterogénea, diversa y compleja. Cualquier análisis puede tornarse superficial, parcial y simple. Argumenta que, independientemente de que se apliquen modelos de desarrollo a favor del mercado o de impulso al Estado, América Latina goza de instituciones ineficientes al no poder distribuir los recursos generados de su crecimiento económico. No es un problema de sólo reformar leyes y normas, se trata de una contrariedad de desarrollo donde el crecimiento económico generado en la región debe traducirse en calidad de vida, gobernanza democrática bajo la égida de la eficiencia y calidad de las instituciones.

Kingstone analiza los modelos de desarrollo, aparentemente contrarios, de isi y las políticas de corte neoliberal. De forma general se reconoce que el modelo is ha promovido el crecimiento económico, el proceso de urbanización y el mejoramiento de la calidad de vida, principalmente en educación, salud y empleo. No obstante, intensificó la deuda externa, aumentó la inflación, limitó el dinamismo económico y atoró sectores como la agricultura. No tuvo capacidad de pasar a una segunda etapa de sustitución de importaciones (de bienes de capital) y, sobre todo, no resolvió la marcada desigualdad social que caracteriza a la región latinoamericana.

En contraste, las políticas de corte neoliberal combatieron eficientemente la inflación y el déficit fiscal, pero fueron incapaces de generar crecimiento económico a la economía doméstica a pesar de los jubilosos éxitos de control de la pobreza (principalmente en Brasil, Chile y México). Los bajos resultados en crecimiento e intensificación de la volatilidad de los capitales crearon incertidumbre en el empleo que estimuló incrementadas tasas en crimen, pobreza y desigualdad, así como de corrupción que no pudieron defender los neoliberales, dando ascenso a posiciones político-ideológicas centrales y de izquierda.

La izquierda latinoamericana, según Kingstone, se mueve en dos direcciones, la moderada y la contestataria (pues no es revolucionaria). La moderada (manifestada principalmente en Brasil, Chile y Uruguay) 
trata generalmente de generar coaliciones con el centro para impulsar pequeños cambios legales y económicos en el modelo, pero sin poner en duda el sistema político y económico neoliberal. La parte contestataria (localizada principalmente en Venezuela, Bolivia y Ecuador) es crítica de la situación actual capitalista y la hegemonía de Estados Unidos. Esta versión impulsa cambios drásticos legales, económicos y sociales en favor de la intervención estatal en el desarrollo. En tanto Argentina, Perú, Paraguay, Nicaragua y El Salvador no presentan características exclusivas que las podrían colocar en una o en la otra corriente. Y México, Colombia y Costa Rica son los máximos representantes de la corriente ideológica llamada de derecha.

El desempeño de cada una de estas versiones indica que, independientemente de su posición político-ideológica, las medidas de corte neoliberal se siguen aplicando (excepto en Venezuela, donde se volvió al modelo IsI). El caso más exitoso ha sido el de la izquierda moderada que maneja el impulso de dichas reformas neoliberales con un carácter «humano», con Brasil como su máximo representante. Con su política de fomento al consumo doméstico y a la innovación tecnológica, Brasil ha mejorado la calidad de vida de sus habitantes, pero no ha superado problemas de corrupción y desigualdad social.

Entonces, si los modelos de desarrollo aplicados en América Latina en los últimos años no han cubierto el objetivo central de generar desarrollo económico, ¿qué es lo que realmente está afectando su desempeño? Según los economistas institucionalistas, el Estado puede proteger los intereses de la sociedad a través de la protección de los derechos de propiedad. El problema radica cuando el Estado construye todo un sistema para proteger sólo los intereses de él mismo o de un grupo social específico. En todo caso, son los pobres quienes han sido fuertemente desposeídos de los derechos de propiedad a favor de las clases media y alta. Para Kingstone, la informalidad de la estructura social, económica y política de los pobres ha estado sustentada en la ausencia de derechos de propiedad.

Los institucionalistas consideran que la política y toma de decisiones está determinada por una serie de factores que tienen que ver con el 
manejo correcto de las instituciones; no obstante, esto no es posible pues las mismas políticas específicas no pueden medir la calidad de la cultura política. Por el contrario, dicho manejo viene de un mejor desarrollo. Son los países desarrollados quienes cuentan con instituciones transparentes y autónomas de la sociedad y del sistema económico que permiten el mejor manejo del desarrollo. Existe una estrecha relación entre calidad de la política y desarrollo. Las instituciones políticas de buena calidad sólo se pueden dar si existe desarrollo.

Para que haya desarrollo es necesario, por tanto, crear instituciones que lo permitan y, con ello, la existencia de la democracia. No existe un camino para ello. Existen propuestas: el desarrollo de instituciones formales está vinculada a una serie de prácticas informales que lo sustenten (cultura, educación, etcétera). La exigencia de justicia y equidad debe partir de los ciudadanos y sus valores. América Latina ha trabajado mucho para fortalecer sus instituciones, aún insuficiente, y quizá, desde la visión de Kingstone, la transparencia y eficiencia de las instituciones puede ser el camino hacia países más justos, más ricos y más equitativos.

Finalmente, con su posicionamiento intermedio entre mercado y Estado, Kingstone expone las debilidades de las corrientes ideológicopolíticas que han explicado el comportamiento socioeconómico de América Latina en los últimos años y supone una propuesta distinta, aparentemente, más práctica que ideológica.

Al final, donde emanan las políticas de corte keynesiano y neoliberal por igual, Kingstone, sin reconocerlo, se adhiere a la posición de la socialdemocracia. Sin cuestionar el funcionamiento de la actual organización socioeconómica basada en el modo de producción capitalista, Kingstone aporta elementos para que América Latina siga manteniendo relaciones de intercambio desigual y producción industrial dependiente de las necesidades de las empresas transnacionales (bajo la explotación y abaratamiento de su abundante mano de obra y recursos naturales) y darle un rostro humano al mejorar la calidad de vida de sus habitantes a través de la eficiencia de las instituciones estatales sin resolver los problemas reales de la región latinoamericana: las consecuencias de la histórica y compleja desigualdad social. 